\title{
The Important Role of Adolescent Health in Gender Equality and Social and Economic Development
}

\author{
Dr. Seram Bhogendra Singh \\ Head, Department of Sociology, S. Kula Women's College, Nambol, Manipur-795134, India \\ drbhogendra@gmail.com
}

\begin{abstract}
The present paper deals with adolescent and its impact on socio-economic development of India along with the issues in gender equality. Adolescent, or the second decade of life, is a period in which an individual undergoes major physical and psychological changes. Alongside this, there are enormous changes in social interactions and relationships. It is a phase in an individual's life rather than a fixed time period; a phase in which an individual is no longer a child but is not yet an adult. Adolescence is a time of opportunity, but also one of risk. It presents a window of opportunity because actions could be taken during this period to set the stage for healthy adulthood and to reduce the likelihood of problems in the years that lie ahead. At the same time, it is a period of risk; a period when health problems that have serious immediate consequences can and do occur such as deaths resulting from road traffic injuries, and sexually transmitted infections and unwanted pregnancies resulting from unprotected sexual activity; a period when problem behaviours which could have serious adverse effects on health in the future such as tobacco smoking and alcohol consumption are initiated. Worldwide more than 1.2 billion are adolescents: this indicates that roughly one in every six persons is an adolescent. About 21\% of Indian population is adolescents (about 243 million). They are the future of the nation, forming major socio-economic and demographic forces of the society. They have specific needs which vary to gender, life circumstances and socio economic conditions. They face challenges like poverty, lack of access to health care services, unsafe environments etc. It is a period of preparation for undertaking greater responsibilities like familial, social, cultural and economic issues in adulthood. The health status of an adolescent determines the health status in his/her adulthood. Many serious diseases in adulthood have their roots in adolescence. Also, many adolescents do die prematurely due to various reasons that are either preventable or treatable and many more suffer from chronic ill-health and disability. We can categorize the health needs of the adolescents broadly into three categories-physical, psychological and social. Methodology: focus group discussion with adolescent population, interview with key population like health workers, officials and community leaders, literature review, used of published and unpublished materials related to the present issues etc.
\end{abstract}

Keywords: Adolescent health, socio-economic, gender equality etc.

\section{Objectives of the study}

a) To explore the correlation between adolescent, gender equality, and adolescent health in the socio-economic development of India;

b) To analyse the necessity of adolescent health in the overall socio-economic development and gender equality of the country.

\section{Research Methodology}

Focus group discussion with adolescent population, interview with key population like health workers, officials and community leaders, literature review, used of published and unpublished materials related to the present issues, collection of primary and secondary sources of data etc.

\section{Introduction}

Adolescents are a group of apparently healthy individuals. The health status of an adolescent determines the health status in his/her adulthood. Many serious diseases in adulthood have their roots in adolescence. Also, many adolescents do die prematurely due to various reasons that are either preventable or treatable and many more suffer from chronic ill-health and disability. We can categorize the health needs of the adolescents broadly into three categoriesphysical, psychological and social. The main health issues faced by the adolescents include: Mental health problems, early pregnancy and childbirth, human immunodeficiency virus/sexually transmitted infection (HIV/STI) and other infectious diseases, violence, unintentional injuries, malnutrition and substance abuse.

Adolescents form a socially important segment of the population. Apart from physical health, a positive social health constitutes holistic health of the adolescents. Prevalence of sexual abuse, violence and physical abuse are increasing among the adolescents. For a long time, there was no organized system to govern and monitor the social needs of adolescents. The Committee on the Gopala krishnan Rights of the Child (CRC, WHO), published guidelines in 2013 on the rights of children and adolescents and issued guidelines on States' obligations to recognize the special health and development needs and rights of adolescents and young people. This has been further envisaged in WHO report in 2014 titled "Health for the world's adolescents".

In India, data on adolescents from national surveys including National Family Health Survey III (NFHS-3), District Level Household and Facility Survey III and Sample Registration System call for focused attention with respect to health and social development for this age group. It has therefore been realized that, investing in adolescent health will yield demographic and economic dividends for India. In view of this, Government of India launched its first comprehensive programme for adolescents, 'Rashtriya Kishor Swasthya Karyakram', during January 2014 which has a sharp focus on adolescents' sexual health. The programme envisages that all adolescents in India are able to realize their full 
potential by making informed and responsible decisions related to their health and well-being.

\section{Global Scenario}

About 1.3 million adolescents died from preventable or treatable causes during 2012 as per WHO reports. Road traffic injuries were the leading cause of death among adolescents. About $15 \%$ of global maternal death occurs among adolescents girls. The major causes for Disability Adjusted Life Years (DALY) in adolescents were given in. Injuries and psychological disorders were the major issues in adolescents. There is an increasing trend in adolescent obesity due to great shift in diet and activity pattern. Nearly $35 \%$ of the global burden of disease has roots in adolescence. Half of all mental health disorders in adulthood start by 14 year of age, most cases are undetected and untreated.

In the South East Asian Region (SEAR), unipolar depressive illnesses in females, and road traffic injuries in males were the major health issues and it remains at the top throughout the years. AIDS has emerged as a third leading cause of DALYs in adolescents in the last decade. These issues need to be addressed for the wellbeing of adolescents.

\section{Adolescent Problem in India}

India has the largest adolescent population in the world. The decadal comparison of State wise distribution of adolescent population is shown in. The distribution of percentage of adolescents among the top and bottom five States are shown in. There were few studies done on the prevalence of diseases and their risk factors and disease pattern among adolescents in these States. Some of the major health problems of adolescent population are briefly discussed below.

\section{Reproductive and Sexual Health}

Adolescents have diverse sexual and reproductive health problems. Some of the important determinants of adolescent reproductive and sexual health are given in. As per NFHS-3 data, $2.7 \%$ boys and $8 \%$ girls reported sexual debut before the age of 15 and most of the sexual activity happens in the context of marriage, this leads to early pregnancy due to social pressure. Even though contraceptive awareness is $94 \%$ among girls aged $15-19$, only $23 \%$ of the married and $18 \%$ of the sexually active unmarried girls in this group, used a contraceptive once at least. All the three NFHS shows almost equal prevalence $(59.1 \%, 59.8 \%$ and $58.2 \%$ ) of pregnant and mothered adolescent and there is a steady increase in percentage of first pregnancy among adolescents $(11.7 \%, 12.4 \%$ and $14.4 \%)$. Early marriage and low contraceptive usage are the reasons behind this trend.

The State wise adolescent fertility rates during the period of 2011 and 2012. Adolescent fertility rates contribute $17 \%$ to the total fertility rate in India and about $14 \%$ of births in women aged below 20 were unplanned. Early and unplanned adolescent pregnancies are highly prone for adverse pregnancy outcomes like eclampsia, low birth weight, early neonatal death and congenital malformation. In addition, $34 \%$ of ever-married adolescent girls (15-19 y) reported that they suffered physical, emotional or sexual violence inflicted by their partner. There is a remarkable decline in these rates as age of marriage raises. So, early marriage also carries the risk of subjecting girls to all forms of violence.

In India $19 \%$ girls and $35 \%$ boys had comprehensive knowledge about HIV/AIDS. Only $15 \%$ young men and women (15-24 y) reported that they received family life or sex education. Eventually due to inadequate knowledge they are at greater risk of exposure to unprotected sex, unethical sexual practice and STIs. In the age group of 15-19 y, among those who had sexual intercourse, $10.5 \%$ of girls and $10.8 \%$ of boys reported having STI or symptoms of STI and $0.07 \%$ of girls and $0.01 \%$ of boys were found to be HIV positive. The awareness regarding transmission of STIs is low among adolescents. This, in addition to social stigma the diseases were often undisclosed, left untreated leading to complications like infertility, pelvic inflammatory disease and cancer.

\section{Nutritional Health}

Adolescents have increased nutritional requirements demanding diet rich in protein, vitamins, calcium, iodine, phosphorus and iron due to rapid growth spurt and increased physical activity. NFHS-3 data shows, in the age group 15$19 \mathrm{y}, 47 \%$ girls and $58 \%$ boys were thin, $56 \%$ girls and $30 \%$ boys were anaemic, $2.4 \%$ girls and $31.7 \%$ boys were overweight and 2/1000 adolescent girls and 1/1000 adolescent boys suffer from diabetes. They are also highly prone for eating disorders like anorexia nervosa or binge eating due to body dissatisfaction and depression.

Use of mass media is higher among adolescents (male $88.2 \%$ and female $71.5 \%$ ). It plays an important role in habit picking and decides their lifestyle pattern. Its influence is clearly shown in a study from Chennai done in the age group 11 to 17 y reporting that, $90 \%$ eat either food or snacks while watching TV, $82 \%$ buy food products and snacks based on advertisement, 59\% skipped outdoor activities for $\mathrm{TV}, 42 \%$ follows diet and $42 \%$ exercise to get the body like their favourite media personality. Television viewing in childhood and adolescence is associated with overweight, poor fitness, smoking and raised cholesterol in adulthood.

\section{Mental Health}

Mental health problems are one of the most neglected issues among adolescent. Mortality and morbidity due to mental disorders in adolescents increased and topped in recent years. A study from Goa, among 16 to 24 y old, shows $3.9 \%$ of youths reported suicidal behaviours with females four times more prone than males. This suicidal behaviour is independently associated with factors like absenteeism, independent decision making, premarital sex, sexual abuse, physical abuse from parents and mental disorders. In India suicide among adolescents is higher than any other age group that is $40 \%$ of suicide deaths in men and $56 \%$ of suicide deaths in women occurred in 15-29 y of age.

The prevalence rate of child and adolescent psychiatric disorders in the community has been found to be $6.46 \%$ and in schools, it was $23.33 \%$ and the reporting systems of psychiatric disorders in children are found to be inadequate. From the above studies it is evident that a considerable proportion of adolescent have mental health problems.

Substance Abuse 
Substance abuse is yet another serious issue as adolescents are ignorant about its consequences. NFHS-3 data shows, in the age group $15-19$, about $11 \%$ of adolescent boys and $1 \%$ of adolescent girls had consumed alcohol, in that $3 \%$ consume it daily. About $29 \%$ boys and $4 \%$ girls use some kind of tobacco. The average age at tobacco use initiation was earliest at $12.3 \mathrm{y}$ and alcohol usage at $13.6 \mathrm{y}$ among adolescents. About $11 \%$ of cannabis users were introduced to it before the age of 15 . Initiating cannabis at this age is strongly associated with the development of Schizophrenia spectrum disorders in adulthood.

\section{Adolescent Health Programmes and Its Ministries}

Adolescent health programmes are implemented by various ministries under the government of India. They provide different types of services targeting adolescent health problems in different areas. Adolescent health programmes, their ministries and the services provided.

\section{Challenges Concerning Adolescent Health}

Though adolescence is usually a healthy period, several risk factors of adult diseases which begin in adolescence can be prevented with proper interventions during this period, though with challenges. Exclusive data pertaining to the adolescent health issues in Indian scenario is not available and hence we used the data pertaining to South East Asia Region for comparison in which India is a major constituent country. The data about important adolescent's health issues in different areas are limited. Hence detailed investigation and reports on adolescent's health issues is the need of the hour.

\section{Reproductive and Sexual Health}

From the studies done in the past, it is evident that adolescent have no proper knowledge regarding STIs and an educational intervention shows significant improvement in the knowledge level of the participant. At this age, curiosity about sexuality increases, they start showing sexual interest in opposite sex. Media also plays a major role in exposing them to sexually explicit materials which make them perpetrators of sexual violence.

\section{Mental Health}

In the past decade mental health problems have emerged as an important cause of adolescent morbidity. Alcohol use disorder and psychiatric problems are the important cause of Years Lost due to Disability. Focus towards these problems in adolescent health programmes happens to be less when compared to Reproductive and Sexual Health. So it is essential to give equal importance to other key areas like mental health services and Behavioural Change Communication towards healthy lifestyle.

\section{Nutritional Problems}

Nutritional requirement are higher among adolescents than any other period of life. Inadequate diet intake at this age leads to stunted growth and delayed sexual maturation. Lot of junk food products are promoted by celebrities with catchy advertisements leading to adaptation of unhealthy food habits. Media influences the diet and lifestyle among adolescents and leads to nutritional disorders by making them sedentary and giving false hopes. Habits like dieting and exercising inspired by a media celebrity cannot be taken as a positive impact, often they do it in an incorrect way and consume low quality protein supplements without proper guidance which may lead to complications like renal failure. Instead of taking balanced diet they starve and end up in anorexia nervosa. These issues can be reduced by routine screening and nutritional education.

\section{Substance Abuse}

Habits like smoking and alcoholism have lifelong impact and potential to cause health problems like coronary heart disease and diabetes in adulthood. Even though there is legal restriction, alcohol and tobacco products are available generously for under-18 age group. Road Traffic Accidents:

Road traffic injuries emerged as a leading cause of death among adolescents. Rash driving, driving without license, drunken driving and use of mobile phones while driving are factors associated with road traffic injuries in young drivers. This can be prevented by strict enforcement of law and by conducting awareness campaign targeting adolescents insisting the need for following safety rules.

\section{Challenges in Parenting}

Parents have greater responsibility in guiding their children but due to cultural barriers they neglect to talk about physical and physiological changes, in consequence of this, growing children learn about sexuality and secondary sex characteristics from their peer groups or other inappropriate sources leads to abnormal social behaviour. Most of the children's psychiatric disorders were unidentified because of parent's ignorance and negligence.

\section{Challenges in Existing Adolescent Health Services}

With so many programmes available, the services have not reached the target group adequately because resources like materials, money and man power are limited. There is no direct access, space for privacy and ideal timing (restrictions in days and time) for the target population. Service providers are not given proper training. For the health care providers it is usually an extra burden because no man power has been allotted separately for adolescent health services. Adolescents have little knowledge about the need of health services. They are scared of revealing personal issues to another person and getting examined by opposite sex health worker. So they themselves act as major obstacle for the services to reach them.

Adolescent health services are not comprehensive, so many schemes exist but these schemes were placed under different ministries and some of the schemes provide the same services as others which may result in unnecessary duplication. In 2014 Ministry of Health \& Family Welfare (MoHFW), launched a comprehensive programme (Rashtriya Kishor Swasthya Karyakram), but similar services provided by MoHFW and other ministries are not going to be terminated. To avoid such confusions and to be cost effective, all the services for adolescents should come under a single programme. It is also essential to develop a screening tool specific for Indian adolescents.

\section{Suggestions and Recommendations}


While planning it is important to identify the felt needs of the adolescents and the services should be demand driven. It is equally important to create awareness among the adolescents about the significance and the need of the services and to motivate them to avail the services. The following recommendations shall be considered for improving adolescent health services.

1) Introduce age appropriate sex education with abuse prevention skills at schools, colleges and also in the community to bridge the knowledge gap in adolescent. With this approach, sexual abuse, early sex debut and unsafe sexual practice can be reduced and the contraceptives usage can be increased. This in turn prevents unwanted pregnancy, AIDS/STIs and its complications.

2) Take step to delay age of marriage through advocacy, counselling and strict enforcement of law. Adults should be educated to prevent early marriage, teenage pregnancy and its complications.

3) Educate Adolescents and parents regarding the nutritional requirements and to adapt diet appropriate for age.

4) Psychological disorders and social misbehaviour can be greatly reduced by giving top priority and effective implementation of mental health services at all levels. Educate parents and teachers to improve the quality of relationship with children to ensure a safe, secure and appropriate environment.

5) All PHC's has to be equipped to deliver AFHS beyond existing days and time restriction. A separate sophisticated wing to treat adolescent at secondary and tertiary care level can be established.

6) Medical officers and the health workers at all level should be given exclusive training in handling adolescents. Health workers of same gender should address the problem of boys and girls separately.

7) Facilitate better relationship of trust and confidence in adolescent to get accurate and detailed information related to their health problems.

8) Counselling should be strengthened by well trained healthcare providers and involve parents and elders of the family in home based counselling.

9) Encourage community participation in mobilizing adolescents to build life skills and to take active part in community programs.

10) Universal coverage of Adolescent friendly clinics is highly recommended. Through that, routine screening of adolescent for health problems, and their risk factors by creating a standardized protocol can be initiated and the services required can be provided.

\section{Conclusions}

To achieve wholesome adolescent health, we need to have a multidimensional approach covering all the adolescent health problems with special emphasis on mental health, behaviour change communication towards healthy lifestyle and positive social environment to acquire life skills. Adolescent friendly clinics need to be widely established throughout India and should achieve universal coverage. Screening of adolescent on regular basis could be an effective tool to control the existing disease and to update occurrence of any new diseases. Empower and involve adolescents in decisions that affect them and facilitate them with every opportunity for developing into a successful adult. Offering such opportunities to the growing children gives them a chance to build a safe, happy, healthy and productive nation in the future.

Exclusive data pertaining to the adolescent health issues in Indian scenario is not available when compared to the other developed countries. Nation and States wise detailed investigation and reports on adolescent's health issues, is the need of the hour. This will help to create better awareness among the stakeholders about the importance of strengthening adolescent health services under a single agency in order to meet their needs.

\section{References}

[1] Bang R, Bang A. A community Study of Gynaecological Diseases in Indian Villages. In Census of India 2011, New Delhi: Office of the Registrar General.

[2] Dasgupta A, Sarkar M. Menstrual hygiene: How hygienic is the adolescent girl? Indian Journal of Community Medicine 2005;33:77-80.

[3] Drakshayani DK, Venkataramiah P. A study of menstrual hygiene among rural adolescent girls. Indian Journal of Medical Sciences 1994;48:13943.

[4] Encyclopaedia of Adolescence: available on website: http://en.wikipedia.org/wiki/Adolescence access on 25/2/2020.

[5] Mehta R. Establishing adolescent health services in a general health facility. Bott S, Jejeebhoy SJ, Shah I, Puri C, editors. Towards adulthood: Exploring the sexual and Reproductive health of adolescents in South Asia. Geneva: WHO; 2003. p. 213-5.

[6] Mensch BS, Bruce J, Greene ME. The unchartered passage: Girls' adolescence in the developing world. New York: The Population Council; 1998.

[7] Merton,R and Nisbet,ed.(1971) Contemporary social Problems, New York: Harcourt Brance \& World.

[8] Zeidenstein and Moore, editors. Learning about sexuality: A practical beginning, New York: The Population Council; 1989.

[9] UNICEF, April 2012, Progress for Children: A report card on adolescents. Socio-demographic profile of adolescents: available from: http: //www. unicef. org/ publications/ files/ Progress_for_Children_-_No._10_EN_04232012.pdf. Access on 14/03/2021

[10] Ministry of Health and Family Welfare Government of India Strategy Handbook. Rashtriya Kishor Swasthya Karyakram. Adolescent Health Division. January 2014, Available from: https://www.dropbox.com/s/0oj4p422y7st4ku/ RKSK\%20Strategy\%20Handbook.pdf.

[11] WHO 2014: Adolescents: health risks and solutions. Media centre Fact sheets Available from: http://www.who.int/mediacentre/factsheets/fs34 $5 / \mathrm{en} /$ access on $25 / 3 / 2021$

[12] Ministry of Health and Family Welfare, Launch of Rashtriya Kishor Swasthya Karyakram and National 
Consultation on Adolescent Health.available from: http://rksklaunch.in/rkskl-strategy.html.

[13] WHO: Maternal, newborn, child and adolescent health. Adolescent health epidemiology Available from:http://www.who.int/maternal_child_adolescent/ epidemiology/adolescence/en/access on 25/3/2021

[14] WHO 2014, Mortality, morbidity and disability in adolescence: Health for the world's adolescents. Top 10 causes of death among adolescents by sex Available

from: http://apps.who.int/adolescent/seconddecade/section/section_3/level3_2.php. access on $14 / 3 / 2021$

[15] C Abouzahr. C. Women's health meeting: trends and projections for mortality and morbidity Available from: http://icpdbeyond2014.org/uploads/browser/file s/ maternal_mortality_ trends_and_projections.pdf. Access on 14/3/2021

[16] UNICEF 2012 : Progress for Children: A report card on adolescents. Adolescent Mortality, Morbidity and Health-Related Behaviours. 10 April 2012. Figure: 4.1. Page 18

[17] Available

Children__No.__or on $14 / 3 / 2021$

[18] B Popkin, P Gordon-Larsen: The nutrition transition: worldwide obesity dynamics and their determinants. International Journal of Available from: http:// www.cpc.unc.edu / projects / nutrans/publications/Popkin\%20Nutr\%20Trans\%20IJ O\%202004.pdf. Access on 14/3/2021

[19] WHO, 2014: Health for world's adolescents: Disability Adjusted Life Years: Combining Mortality and Morbidity. Available from: http://public.tableausoftware.com /profile/ digital team \#!/ vizhome/shared/FPXZ7PPMR. access on $14 / 3 / 2021$

[20] Census of India 2011, C Chandramouli: Release of social and cultural tables: Age. Data highlights. Available

from: http://www.slideserve.com/varden/social-andcultural-tables-age. IIPS: National Family Health Survey (NFHS-3), 2005-06: India: Volume I. Available from: http://www.rchiips.org/nfhs/NFHS3\%20Data/VOL-1/India _volume _ I _ corrected_17oct08.pdf. access on 14/3/2021

[21] T Ganchimeg, E Ota, N Morisaki, M Laopaiboon, P Lumbiganon, J Zhang, et al. Pregnancy and childbirth outcomes among adolescent mothers: a World Health Organization multi-country study. BJOG. 2014;121(s1):40-48.

[22] R Hancox, B Milne, R Poulton. Association between child and adolescent television viewing and adult health: a longitudinal birth cohort study. The Lancet. 2004;364(9430):257-62. [PubMed] [Google Scholar]

[23] A Pillai, T Andrews, V Patel. Violence, psychological distress and the risk of suicidal behaviour in young people in India. Int J Epidemiol. 2009; 38(2):459-69. PubMed Google Scholar]

[24] V Patel, C Ramasundarahettige, L Vijayakumar, J Thakur, V Gajalakshmi, G Gururaj, et al. Suicide mortality in India: a nationally representative survey. The Lancet. 2012; 379(9834):2343-51. PMC free article PubMed Google Scholar

[25] S Malhotra, B Patra. Prevalence of child and adolescent psychiatric disorders in India: a systematic review and meta-analysis. Child and adolescent psychiatry and mental health. 2014; 8(1):22. PMC free article PubMed Google Scholar Go to: 